\title{
Implementations Related to the Use of Antibiotics and Data Sources Used by Community Pharmacists in the Northern Cyprus
}

\author{
Kaya Süer', Sanda C̣alı², Aslı Aykaç3 ${ }^{[0]}$ \\ 'Department of Infectious Diseases and Clinical Microbiology, Near East University, School of Medicine, Nicosia, Cyprus \\ 2Department of Public Health, Near East University School of Medicine, Nicosia, Cyprus \\ ${ }^{3}$ Department of Biophysics, Near East University School of Medicine, Nicosia, Cyprus
}

ORCID ID of the author: A.A. 0000-0002-4885-5070.

Cite this article as: Süer K, Çalı S, Aykaç A. Implementations Related to the Use of Antibiotics and Data Sources Used by Community Pharmacists in the Northern Cyprus. Cyprus J Med Sci 2019; 4(I): 28-33.

\section{BACKGROUND/AIMS}

As the bacterial resistance to antibiotics became one of the major problems in today's world, a solution to this problem is possible through a common awareness of the doctor who prescribes antibiotics, the pharmacist who sells them, and the patient who consumes them. The aim of this study was to determine the sales ratio of non-prescription antibiotics in pharmacies, which is the most common category of the sold antibiotic group according to the pharmacists' records due to the received prescriptions, and to detect the relationship between the resources of drug information and the sociodemographic data.

\section{MATERIAL and METHODS}

A total of 84 pharmacies out of 168 pharmacies located in the Northern Cyprus were included in the study with a $50 \%$ stratified systematic sampling.

RESULTS

This study was carried out in the first and the second trimester of 2014 (0I January-30 June), and the daily sale of antibiotics was found to be $41.5 \%$. In addition, the most purchased antibiotics were discovered to be the penicillin with $76.2 \%$, and on the other hand, the disease for which antibiotics were most commonly prescribed was found to be the upper respiratory tract infection with $86.9 \%$. When the level of self-awareness of the pharmacists was examined, it was discovered that they were highly knowledgeable about drug indications, as well as their side effects.

\section{CONCLUSION}

The rate of the use and sale of non-prescribed antibiotics in the Northern Cyprus has been found to be at a higher level compared to the rates in many developed countries. According to the new legislation for 2016, the rate of the use and sale of non-prescribed antibiotics is expected to be decreasing in the future.

Keywords: Community pharmacist, sources of drug information, knowledge of drugs, Cyprus

\section{INTRODUCTION}

As the bacterial resistance to antibiotics became one of the major problems in today's world, a solution to this problem is possible through a common awareness of the doctor who prescribes antibiotics, the pharmacist who sells them, and the patient who consumes them. The rate of non-prescribed sales differs from one country to another, and it is known that the worldwide rate of non-prescribed antibiotics sales from public pharmacies is approximately $50 \%$ ( $1-5$ ). Except in the North America and countries in the Northern Europe, accessing non-prescription antimicrobial drugs is possible throughout the rest of the world. Studies in developed European countries, including the United Kingdom, where the use of antibiotics is under strict control, have shown that the use of non-prescribed antibiotics is $14 \%-37 \%$. According to the same study, it was emphasized that $47 \%$ of the non-prescribed antibiotics were maintained from the public pharmacies.

The use of non-prescribed antibiotics arises substantially from the lack of laws and deficiencies in regulations, especially when the rates are compared between the developed and developing countries. The use of non-prescribed antibiotics in developing countries like Nigeria (76\%) is high due to lack of laws and inadequate regulations (6-II). The main prob- 
lem that arises as a result of non-prescribed antibiotic use is increased antibiotic resistance, which triggers the existing problems (12). In addition, an increased cost of treatment and the side effects of the drugs are known to be important consequences of the non-prescribed antibiotic use (I3).

The aim of this study is to determine the rate of the non-prescribed antibiotic sales in pharmacies, the mostly sold antibiotic group according to the pharmacists' records, and to detect the level of general knowledge as well as the self-assessment of pharmacists' own levels of knowledge; also the study intends to investigate the relationship between non-prescribed sales and the knowledge levels together with the use of data sources, if any.

\section{MATERIAL and METHODS}

\section{Study Design}

A list of 84 pharmacies out of 168 pharmacies located in the Northern Cyprus (Nicosia, Kyrenia, Famagusta, and Morphou)

TABLE I. Sociodemographic Characteristics of Pharmacists

\begin{tabular}{|c|c|c|c|c|}
\hline Parameters $(n=84)$ & & & & \\
\hline Location & Nicosia & Kyrenia & Famagusta & Morphou \\
\hline$n(\%)$ & $36(42.9)$ & $16(19.0)$ & $26(31.0)$ & $6(7.1)$ \\
\hline Age in years & $<50$ & $\geq 50$ & & \\
\hline$n(\%)$ & $42(50.0)$ & $42(50.0)$ & & \\
\hline Gender & female & male & & \\
\hline$n(\%)$ & $57(67.9)$ & $27(32.1)$ & & \\
\hline Educational level & $\mathrm{BSc}^{\mathrm{a}}$ & $\mathrm{MSc}^{b}$ & & \\
\hline$n(\%)$ & $69(82.1)$ & $15(17.9)$ & & \\
\hline $\begin{array}{l}\text { Country where the } \\
\text { bachelor's degree } \\
\text { was obtained }\end{array}$ & $N C^{c}$ & Turkey & UK & \\
\hline$n(\%)$ & $3(3.6)$ & $73(86.9)$ & $8(9.5)$ & \\
\hline $\begin{array}{l}\text { Years of experience } \\
\text { as a community } \\
\text { pharmacist }\end{array}$ & $<10$ years & $\geq 10$ & & \\
\hline$n(\%)$ & $19(12.7)$ & $65(87.3)$ & & \\
\hline
\end{tabular}

TABLE 2. Group of the Most Sold Antibiotics and Indications

n

$\%$

\section{The group of antibiotics}

Penicillin derivate

Cephalosporins

Macrolides

Quinolones

Indications

Urinary tract infections

Dermatologicalinfections was obtained from the 2014 Turkish Medical Association Health Guide published by the Cyprus Turkish Medical Association. Those 84 pharmacies were selected according to the $50 \%$ stratified systematic sampling, and a questionnaire was distributed to all.

Necessary approval were received from the Near East University Medical Research Ethics Committee the pharmacists concerned were asked to fill out and sign a consent form by one of the researchers of the study, a specialist in infectious diseases and clinical microbiology, in the period from June to September 2014.

\section{Methods}

The sociodemographic characteristics, non-prescribed antibiotics sold, the most sold antibiotic group, the data sources, and the self-declaration of their own levels of knowledge were included in the questionnaire. The self-assessed knowledge levels of the pharmacists were evaluated by the 5-pointLikert Scale, from very poor (I) to excellent (5). Data sources used by the pharmacists were the following: Vademecum, RxMediaPharma, British National Formulary (BNF), Drug information prepared by the Turkish Pharmacists Union (TEBRP), pharmacology books, colleagues, the Internet, lecture notes, and consulting colleagues and other professionals.

\section{Statistical Analysis}

For statistical analysis, Statistical Package for the Social Sciences version I5.0 (SPSS Inc., Chicago, IL, USA) was used, and the chi-squared test was applied. A $p$-value $<0.05$ was accepted as significantly different.

\section{RESULTS}

Considering the distribution of pharmacies in the Northern Cyprus, it can be seen that the most pharmacists are located in Nicosia (42.9\%). A total of $86.9 \%$ of the pharmacists graduated in the Republic of Turkey, $67.9 \%$ received only a bachelor's degree, and $82.1 \%$ were female. In addition, $87.3 \%$ of pharmacists had been working as pharmacists for over 10 years (Table I).

When asked if they gave drugs to patients without any prescription, 82 (97.6\%) pharmacists replied yes. When the daily antibiotic sale rates were examined, it was determined that the pharmacists were selling more than 10 antibiotics per day. Pharmacists selling less than 10 antibiotics a day had an antibiotic prescription rate of $56.2 \%$, while pharmacies selling more than 10 antibiotics a day had an antibiotic prescription rate of $67.5 \%$.

The sale rate of penicillin-derived drugs was $76.2 \%$, and the sale of penicillin among other antibiotic strains was identified as the most common drug. Moreover, it was found out that antibiotics have been used most often in the treatment of upper respiratory tract complaints $86.9 \%$ (Table 2 ).

Pharmacists' self-assessment of their own level of knowledge on drugs was investigated through the 5-pointLikert Scale. None of the questioned parameters were selected as very bad (I) (Figure I). Generally, pharmacists had a positive view of themselves with regards to medical knowledge of antibiotics. Their strong areas were selected to be issues relating to indications and side effects. Pharmacists determined that they felt they were weak 
in the areas of pharmacological properties and drug interactions, again according to their own statements (Figure I).

TABLE 3. Sources of Drug Information Used by Community Pharmacists $(n=84)$

\begin{tabular}{|c|c|c|}
\hline Sources of Drug Information $(n=84)$ & $\mathbf{n}$ & $\%$ \\
\hline Vademecum medication guide' & 74 & 88.1 \\
\hline RxMediaPharma ${ }^{2}$ & 31 & 36.9 \\
\hline $\mathrm{BNF}^{3}$ & 13 & 15.5 \\
\hline TEBRP $^{4}$ & 4 & 4.8 \\
\hline Pharmacologybooks & 19 & 22.6 \\
\hline Colleague & 24 & 28.6 \\
\hline Internet & 57 & 67.9 \\
\hline Lecture notes & 12 & 14.3 \\
\hline Otherhealth personnel & 13 & 15.5 \\
\hline
\end{tabular}

When drug information sources used by pharmacists were examined, it was seen that the Vadamecum medical guide was the most frequently used printed (88.1\%) information source, while the Internet took the second place with $67.9 \%$ (Table 3).

When considering the impact of the independent variable on the level of knowledge, it can be observed that indications, pharmacological properties, contra-indications, side effects, drug interactions, and warnings were not affected by the level of knowledge in specific situations or bioequivalence issues. The level of education affects the variable posology and the method of administration regarding the level of knowledge only. Nevertheless, those with a master's degree (Master of Science, MSc) evaluated their knowledge level as perfect compared to those without it (Table 4).

Statistically, there was no relationship between the use of Vademecum, BNF, TEBRP, RxMediaPharma, Internet, lecture notes, and consulting colleagues or other health personnel and the level of education. It was determined that pharmacology refer-

TABLE 4. Dependent Variables Affected by the Level of Education, Seniority, and the Age of Pharmacist

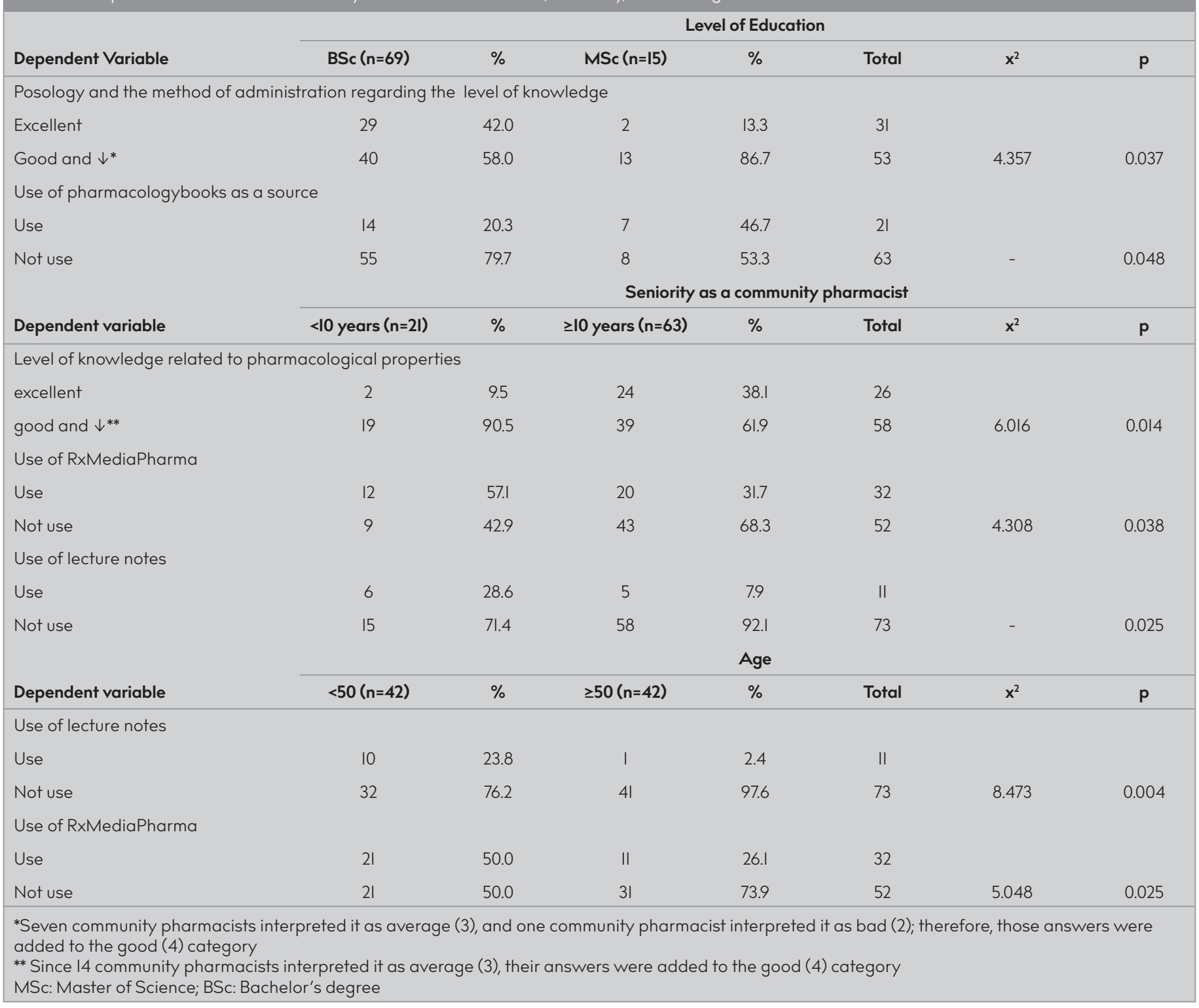




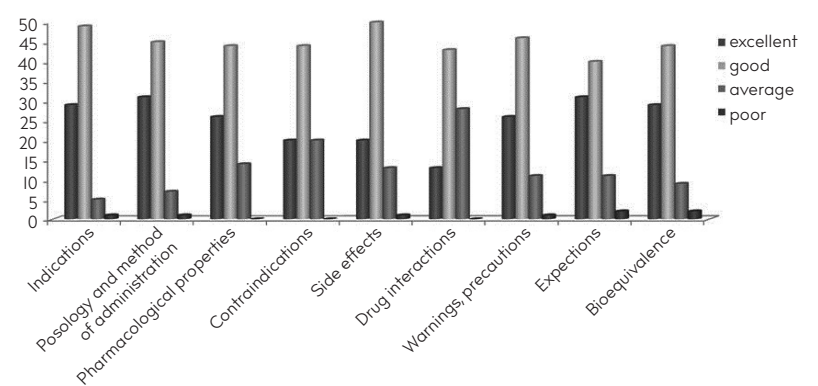

FIGURE I. Pharmacists' self-assessed knowledge of drugs

ence books were the only variable among the sources used to access the information that was affected by the level of education. It was clearly seen that the use of a pharmacology book as a source by pharmacists with a master's degree was twice as frequent as in those without it (Table 4).

The level of knowledge related to pharmacological properties seems to be only affected by the seniority as an independent pharmacy. According to the statements by the pharmacists who participated in the survey, there is a statistically significant relationship between the knowledge level regarding the pharmacological properties and the seniority as pharmacist. In pharmacists' own words, as the years of being in the independent pharmacy practice increase, the level of knowledge related to the pharmacological properties of drugs increases accordingly. Pharmacists who had been working as community pharmacists for a period greater thanl0 years evaluated their knowledge level regarding the pharmacological features as perfect, approximately 4 times higher than those who had been working as community pharmacists for a period shorter than 10 years (Table 4).

Statistically, no significant relationship was found between the use of Vademecum, BNF, TEBRP, the Internet, pharmacology reference books, and consulting colleagues or other health personnel and seniority as a community pharmacist. However, data indicated that there was a clear relationship between lecture notes and the use of RxMediaPharma with the seniority of community pharmacists. This revealed that the pharmacists who worked as community pharmacists for less than 10 years referred to RxMediaPharma and lecture notes as sources of information more than those with less experience in terms of the years of practice (Table 4).

The age group showed no major relationship between the use of Vademecum, BNF, TEBRP, the Internet, and pharmacology reference books and consulting with colleagues or other health personnel, yet there was a significant relationship between lecture notes and the use of RxMediaPharma with the age group. Lecture notes and RxMediaPharma were used more frequently by the pharmacists who were younger than 50 than those who were older (Table 4). According to pharmacists' own assessments, age had no effect on variables regarding the pharmacists' level of knowledge.

\section{DISCUSSION}

Every country has its own national health system that reflects its history, economic development, and the political ideology within its territory. In this respect, it would be possible to say that there is no health system in the Northern Cyprus that could provide adequate basic health services and health insurance encompassing everyone (14). The rate of non-prescribed antibiotics purchased from public pharmacies is found to be $41.5 \%$ in the Northern Cyprus, compared with the studies conducted in Greece, Italy, Malta, and Spain (47\%), and Egypt $(50.4 \%)(15,16)$.

If we consider countries such as Israel, with a rate of $4 \%$, and Nigeria, with a much higher rate $(76 \%)$, it would be possible to think that the type of health system in these countries that are welfare-oriented plays a significant role in providing more efficient health services $(14,17,18)$.

In pharmacies selling less than 10 antibiotics $(n=79)$, the sale rate of non-prescription drugs is $42.82 \%$, and in pharmacies selling 10 antibiotics and more $(n=5)$, the daily sale rate is $32.5 \%$. This situation highlights that pharmacies that have existed for a longer time and selling 10 antibiotics or more have a greater reputation and have an established clientele of patients as customers.

According to the Malaysia Medical Statistics 2005, among the most widely prescribed drugs, the penicillin group of antibiotics came at the top with $47 \%(19,20)$. In the study conducted in primary health care units in Malaysia in 2004 by Teng et al. (2I), it was determined that $50 \%$ of antibiotics were prescribed for the treatment of upper respiratory tract infections. In another study, it was observed that amoxicillin, which is a derivative of penicillin, was prescribed for common cold at a rate of 54\% (22). Similarly, in our study, we found that the most applied group of antibiotics in the first 6 months of 2014 were penicillin derivatives at $76.2 \%$ for the treatment of upper respiratory tract complaints at the rate of $86.9 \%$. In this regard, the rate of prescription of penicillin in our research group was found to be more than one and a half times higher than the rate in Malaysia.

According to the data from the European Surveillance of Antibiotics Consumption (ESAC) Project carried out in 2003 and including25 European countries, the most used antibiotics for the upper respiratory tract infections is penicillin, which is derived from antibiotics (23). It has been reported that the most common causative agents of the upper respiratory tract infections are viruses, and even though it is a known fact that antibiotic treatment is has no clinical benefit in such cases, antibiotics remain overconsumed (24). The reasons for which the rates are so high in our study can be identified as prescribed and non-prescribed antibiotic sales. Moreover, when all types of penicillin derivatives are examined as a whole, we can also observe that doctors may prescribe antibiotics unnecessarily and that the pharmacists sell non-prescribed antibiotics. In France, one campaign aimed to reduce the use of antibiotics for upper respiratory tract infections across the country, which resulted in a $26.5 \%$ decrease in the use of antibiotics between the years 2002 and 2007 (25).

In the study conducted by Jawla et al. (26), which investigated data on drug interactions and drug dosages, it was specified that $73 \%$ of the pharmacists had information concerning drug interactions. The same study specified that $35 \%$ of the pediatric and geriatrics doses were calculated by pharmacists. A total of $66.7 \%$ of pharmacists in the Northern Cyprus assessed their level of knowledge on the drug interactions as excellent or good. 
Pharmacists stated that they calculated the drug doses themselves in pregnant, pediatric and geriatric patients. And in the calculation of drug doses, $84.5 \%$ of the pharmacists stated that they were either excellent or good. Northern Cyprus pharmacists indicated that their knowledge about the side effects of the medication was excellent or good at the rate of $83.3 \%$ and as average at the rate of $15.5 \%$. Chan et al. (13) stated in their study that $67 \%$ of the independent pharmacists specified the importance of having a place to get information about the adverse drug reactions, and $28 \%$ of them specified it as average. This result confirms our research concerning the self-confidence in the field of drug side effects.

In a study conducted in Hong Kong, the rate of independent pharmacists consulting pharmacist colleagues very frequently to get information on drugs was 14\%, whereas frequentconsultation remained at $38 \%$. This method of access to information is lower in the Northern Cyprus (28.6\%) (2I). Chen et al. (13) reported that the rate of very frequent consultation of other health personnel was at $5 \%$ and frequent consultation was at $13 \%$. Independent pharmacists consulting other health personnel in the Northern Cyprus had similar rates as the study in Hong Kong (15.5\%).

Among the reasons as to why pharmacists have a higher preference for consulting other health personnel and pharmacist colleagues to access information rather than consulting $\mathrm{Va}$ demecum or the Internet, contrary to hospital pharmacists, are various issues such as the absence or restricted numbers of easily accessible doctors to consult, as well as their workload.

In addition, it would be possible to think that hospital pharmacists receive significantly different types of questions in terms of drug information from other health workers, whereas it is generally considered that answering questions from the community is the role of an independent pharmacist.

Answers to questions relating to renewed data sources by Jawline et al. (26) showed that $64 \%$ of pharmacists preferred books and magazines, $31 \%$ medical representatives, and $5 \%$ of the pharmacists stated that they used other sources.

The Vademecum medical guide was determined to be the first data source at $88.1 \%$ compared to the books and magazines used by the Northern Cyprus pharmacists as a source of information. The study determined that the utilization rate of the BNF in the Northern Cyprus is (15.5\%), contrary to the rate of BNF used at a rate of $67 \%$ in the Northern Cyprus (13). In the study conducted in Hong Kong, the use of Goodman and Gilman's The Pharmacological Basis of Therapeutics book as a source of information was $5 \%$, compared to the use of pharmacology books in the Northern Cyprus at 22.6\% (I3). As the Internet is one of the easiest and fastest ways to access information in today's world, it appeared as the second most common source with $67.9 \%$ preferred by the Northern Cyprus pharmacists to access information. The majority of pharmacists in the Northern Cyprus work as independent pharmacists, and therefore journal and periodicals on pharmacy or pharmacotherapy sources are not easily accessible. Also, the use of sources such as the Internet and Vademecum medication guide instead of standard texts are more popular as they are considered to be updated and revised. Medical representatives rarely visit pharmacies in the
Northern Cyprus because of the scarcity of population. For this reason, medical representatives are not seen as a drug information source in this country.

Pharmacists with an MSc degree evaluated their knowledge levels on posology and administrative methods as excellent at a low rate of $13.3 \%$ compared to those without the degree. This situation mostly depended on the increase of awareness with regards to education. As the seniority increases, the level of knowledge on the pharmacological features of drugs is thought to be increasing as well.

A limited use of RxMediaPharma as an interactive drug reference source by the pharmacists who are aged $\geq 50$ years, as well as those with $\geq 10$ years of experience as independent pharmacists, is thought to be due to the fact that RxMediaPharma is more up to date and hence may not be as known as the other reference sources.

We believe that pharmacists with an MSc degree using pharmacology books two times more frequently than those with a $\mathrm{BSc}$ degree are more likely to be effective in raising awareness due to the education they have received.

We discovered that independent pharmacists who are aged $<50$ years have worked as independent pharmacists $<10$ years use their lecture notes to access the information concerning drugs at a higher rate than the pharmacists whose work experience is $\geq 10$ years and are aged $\geq 50$ years. This is probably because young graduates keep and use their lecture notes and have upto-date knowledge from their university course.

Unnecessary and excessive use of antibiotics creates a problem that is not simply a personal problem, but a global one. The problem primarily encompasses providing more effective health services, limiting doctor prescriptions of antibiotics, and preventing pharmacists from selling any kind of non-prescription antibiotics. Overuse and sale of antibiotics can be prevented by modifying and restricting the existing regulations and training the public $(16,17)$. Campaigns can be arranged as in France to reduce the inappropriate use of antibiotics throughout the country. Such a campaign could also aim at reducing the prescription of antibiotics by doctors, as well as veterinarians according to the updated guidelines by the country's surveillance results (14).

For pharmacies, the law that no antibiotics could be sold without a prescription came into force on April Ist, 2016. To determine the attitudes and behaviors of pharmacist in the sale of antibiotics in the Northern Cyprus, new studies should be conducted to compare the pre- and post-law conditions.

Our findings signify the indiscriminate and high rate of antibiotic use in the Northern Cyprus. Considering a high number of students and tourists coming from various parts of the world to Northern Cyprus, it may be considered that the antibiotic resistance is effective in a much wider geographical area.

Ethics Committee Approval: Ethics committee approval was received for this study from the Ethics Committee of Near East University Medical Research Ethics Committee (Approval Date: 14.II.2013, Approval Number: NEU/2013/23/094). 
Informed Consent: Written informed consent was obtained from the patients who participated in this study.

Peer-review: Externally peer-reviewed.

Author contributions: Concept - K.S., A.A.; Design - K.S. , S.C., A.A.; Supervision - K.S.; Resource - K.S.; Materials - K.S., A.A.; Data Collection and/or Processing - K.S., S.C., A.A.; Analysis and/or Interpretation - K.S., S.C., A.S.; Literature Search - K.S., A.A.; Writing - K.S., S.C., A.A.; Critical Reviews - K.S., S.C., A.A.

Conflict of Interest: The authors have no conflicts of interest to declare.

Financial Disclosure: The authors declared that this study has received no financial support.

\section{REFERENCES}

I. Uzun S, Arslan F. Medication Errors. Türkiye Klinikleri J Med Sci 2008; 28: 217-22.

2. Dameh M, Green J, Norrris P. Over-the-counter sales of antibiotics from community pharmacies in Abu Dhabi. Pharm World Sci 20l0; 32: 643-50. [CrossRef]

3. Volpato DE, Souza BV, Rosa LG, Melo LH, Daudt CA, Deboni L. Use of Antibiotics without Medical Prescription. Braz J Infect Dis 2005; 9: 288-9I. [CrossRef]

4. Llor C, Costs JM. The sale of antibiotics without prescription in pharmacies in Catalonia, Spain. Clin Infect Dis 2009; 48: 1345-9. [CrossRef]

5. Contopoulos-lonnidis DG, Koliofoti ID, Koutroumpa IC, Giannakakis IA, loannidis JP. Pathways for inappropriate dispensing of antibiotics for rhinosinusitis: a randomized trial. Clin Infect Dis 2001; 33: 76-82. [CrossRef]

6. Fakunle $Y M$, Watkins $B$. Influence of self-medication on prevalence and antibiotic sensitivity of N. gonorrhoeae in Zaria (Nigeria). East Afr Med J 1976; 53: 693-6.

7. Biswas M, Roy MN, Manik IN, Hossain SMd, Tapu TA, Moniruzzaman Md, et al. Self medicated antibiotics in Bangladesh: a cross-sectional health survey conducted in the Rajshahi City. PMC Public Health 2013; 4: 504-I0. [CrossRef]

8. Al-Azzam Sl, Al-Husein BA, Alzoubi F, Masadeh MM, Al-Horani S. Self-medication with antibiotics in Jordanian population. BMC Public Health 2014; 14: 847.

9. Togoobaatar $\mathrm{G}$, Ikeda N, Ali M, Sonomjamts M, Dashdemberel S, Mori R, et al. Survey of non-prescribed use of antibiotics for children in an urban community in Mongolia. Bull World Health Organ 20I0; 88: 930-6. [CrossRef]

10. Saradamma RD, Higginbotham N, Nichter M. Social factors influencing the acquisition of antibiotics without prescription in Kerala State, south India. Soc Sci Med 2000; 50: 89|-903. [CrossRef]
II. Okumura J, Wakai S, Umenai T. Drug utilisation and self-medication in rural communities in Vietnam. Soc Sci Med 2002; 54: 1875-86. [CrossRef]

12. Bax RP, Anderson R, Crew J, Fletcher P, Johnson T, Kaplan E, et al. Antibiotic resistance: what can we do? Nat Med 1998; 4: 545-6. [CrossRef]

13. Chan TYK, Leet KKC, Critchley JAJH. The needs and sources of drug information among pharmacists in Hong Kong. J Clin Pharm Ther 1996; 21: 325-30. [CrossRef]

14. Sargutan AE. 84 Ülke ve Türkiye'nin Karșılaștırılmalı Sağlık Sistemleri. Sargutan: Academic; 2010. p.1687-1707.

15. Benjamin H, Smith F, Motawi MA. Drugs dispensed with and without a prescription from community pharmacies in a conurbation in Egypt. East Mediterr Health J 1996; 2: 506-14.

16. Okeke IN, Lamikanra A, Edelman R. Socioeconomic and behavioral factors leading to acquired bacterial resistance to antibiotics in developing countries. Emerg Infect Dis 1999; 5: 18-27. [CrossRef]

17. Morgan DJ, Okeke IN, Laxminarayan R, Perencevich EN, Weisenberg S. Non-prescription antimicrobial use worldwide: a systematic review. Lancet Infect Dis 20II; II: 692-70I. [CrossRef]

18. Grigoryan L, Haaijer-Rysjamp FM, Burgerhof JG, Mechtler R, Deschepper R, Tambic-Andrasevic A, et al. Self-medication with antimicrobial drugs in Europe. Emerg Infect Dis 2006; 12: 452-9. [CrossRef]

19. Malaysian statistic on medicine 2005. Pharmaceutical Services Division and the Clinical Research Centre. Ministry on Health Malaysia. (Accessed 25 Jan 20l8) Available from: URL: http://www.crc. gov.my/nmus.

20. Oh AL, Hassali MA, Al-Haddad MS, Sulaiman SAS, Shafie AA Awaisu A. Public knowledge and attitudes towards antibiotic usage: a cross-sectional study among the general public in the sate of Penang, Malaysia. J Infect Dev Ctries 20II; 5: 338-47. [CrossRef]

21. Teng CL, Achike FI, Phua KL, Norhayati Y, Nurjahan MI, Nor AH, et al. General and URTI-specific antibiotic prescription rates in a Malaysian primary care setting. Int J Antimicrob Agents 2004; 24: 496-50I. [CrossRef]

22. Mainous AG, Hueston WJ, Clark JR. Antibiotics and upper respiratory infection: do some folks think there is a cure for the common cold. J Fam Prac 1996; 42: 357-61.

23. Holloway K, Dijk LV. The World Medicines Situation 20II, Rational Use of Medicines. WHO Geneva 20II; I-22

24. Gonzales R, Steiner JF, Sande MA. Antibiotic prescribing for adults with colds, upper respiratory tract infections, and bronchitis by ambulatory care physicians. JAMA 1997; 278: 901-4. [CrossRef]

25. Sabuncu E, David J, de-Bauduin B, Pe'pin S, Leroy M, Pierre-Yves Boe, et al. Significant Reduction of Antibiotics Use in the Community after a Nationwide Campaign in France. 2002-2007. Plos Med 2009; 6: 1-9. [CrossRef]

26. Jwala S, Gupta AK, Kumar V, Pardeep N, Dube OP. Community Pharmacists - Self Assessment. Scholars Research Library 20I0; 2: $415-20$ 